\title{
Beliefs and perceptions about the causes of breast cancer: a case-control study
}

\author{
Allyson K Thomson ${ }^{1 *}$, Jane S Heyworth ${ }^{2}$, Jennifer Girschik ${ }^{2,3}$, Terry Slevin ${ }^{4}$, Christobel Saunders ${ }^{5}$ and Lin Fritschi ${ }^{6}$
}

\begin{abstract}
Background: Attributions of causality are common for many diseases, including breast cancer. The risk of developing breast cancer can be reduced by modifications to lifestyle and behaviours to minimise exposure to specific risk factors, such as obesity. However, these modifications will only occur if women believe that certain behaviours/lifestyle factors have an impact on the development of breast cancer.

Method: The Breast Cancer, Environment and Employment Study is a case-control study of breast cancer conducted in Western Australia between 2009 and 2011. As part of the study 1109 women with breast cancer and 1633 women without the disease completed a Risk Perception Questionnaire in which they were asked in an open-ended question for specific cause/s to the development of breast cancer in themselves or in others. The study identified specific causal beliefs, and assessed differences in the beliefs between women with and without breast cancer.

Results: The most common attributions in women without breast cancer were to familial or inherited factors (77.6\%), followed by lifestyle factors, such as poor diet and smoking (47.1\%), and environmental factors, such as food additives (45.4\%). The most common attributions in women with breast cancer were to mental or emotional factors (46.3\%), especially stress, followed by lifestyle factors (38.6\%) and physiological factors (37.5\%), particularly relating to hormonal history.

Conclusions: While the majority of participants in this study provided one or more causal attributions for breast cancer, many of the reported risk factors do not correspond to those generally accepted by the scientific community. These misperceptions could be having a significant impact on the success of prevention and early detection programs that seek to minimise the pain and suffering caused by this disease. In particular, women who have no family history of the disease may not work to minimise their exposure to the modifiable risk factors.
\end{abstract}

Keywords: Western Australia, Breast cancer, Causes, Beliefs, Case-control

\section{Background}

Breast cancer is one of the most commonly diagnosed invasive cancers and it accounts for a quarter of the female cancers diagnosed annually in Australia [1]. In Western societies it is estimated that one in nine women will have breast cancer before the age of 85 [1]. Increasing age, reproductive factors, mammographic density and, in around $9 \%$ of cases, genetic factors and family history are all known risk factors for breast cancer $[2,3]$. A range of factors, such as dietary fat intake, and solvent and pesticide exposure, have also been implicated as potential risk factors but the evidence so far has been

\footnotetext{
*Correspondence: Allyson.Thomson@curtin.edu.au

${ }^{1}$ School of Occupational Therapy and Social Work, Curtin University, GPO Box U1987, Perth, WA, Australia 6845

Full list of author information is available at the end of the article
}

inconclusive [4-6]. For most cases of breast cancer, the true cause remains unknown [6].

Studies worldwide have identified many factors to which women with breast cancer attribute their condition, including stress and other psychosocial factors; knocks, bruises or injury to the breast; religious causes; chemicals, food additives; proximity to electronic equipment or overhead power lines; viral or bacterial infection; and bad luck [7-9], although there is limited evidence to support the attributions [10,11]. Women without breast cancer also frequently identify similar risk factors when asked about their beliefs about the causes of breast cancer [12].

This study aimed to investigate perceptions about breast cancer causation in a study of women participating in a 
case-control study of breast cancer. Specifically, we aimed to investigate whether women attributed specific cause/s to the development of breast cancer in themselves or in others; what these causal beliefs might be; and to explore whether there may be differences in beliefs between women with breast cancer and women without the disease.

Understanding how women attribute breast cancer causation is important information for health promotion, including breast awareness and promotion of screening programmes, clinical care and policy development. Causal attributions are known to affect the responses of women to health messages and their adoption of various behaviours aimed at risk reduction, including mammographic screening [13,14]. A poor understanding of known risk factors would highlight a need for health promotion messages to improve the knowledge and awareness of true risk factors. This would allow women to make more informed choices in adopting behaviours that influence their risk of developing and successfully treating the disease.

This paper describes the beliefs regarding breast cancer causes held by women in Western Australia with and without the condition.

\section{Method}

Data for this study were collected as part of the Breast Cancer, Environment and Employment Study (BCEES), a case-control study of breast cancer conducted in Western Australia between 2009 and 2011 [15-18]. Within BCEES 1205 women with breast cancer diagnosed within the previous six-months (case women) from the WA Cancer Registry, and 1789 age-group matched women selected randomly from the electoral roll (control women) were recruited.

\section{Recruitment procedure and data collection Data collection}

Consenting BCEES participants, 1205 with breast cancer (response fraction: 57.8\%) and 1789 without breast cancer (response fraction: $41.1 \%$ ), completed an initial questionnaire which comprised sections on demographics, reproductive history, family history of breast cancer, sleep habits, employment history, lifetime physical activity, lifestyle, and pesticide exposure. Information about breast cancer stage and treatment was not sought.

Of the eligible women who did not participate, those who refused were older compared with those who did not respond. Case women who did not respond were more likely to live in very remote areas ( $4 \%$ compared with $2 \%$ who refused). There were no differences in socio-economic status between women who participated and those who did not.
After completion and return of the initial questionnaire participants were mailed a Risk Perception Questionnaire (RPQ). The RPQ consisted of a series of possible exposures and the woman was asked if each exposure increased the risk of breast cancer, decreased it, had no effect or they didn't know [paper submitted].

The RPQ also included one of two possible openended questions: case women were asked "What do you believe caused your breast cancer?" while control women were asked "What do you believe causes breast cancer?". We allowed space for approximately 8-10 sentences. The RPQ was completed and returned by 1109 (92.0\%) of case participants and by 1633 (91.3\%) of control participants.

Written responses from the RPQ were converted into digital text using Cardiff TeleForms ${ }^{\circ}$ software and reviewed by project staff for accuracy and completeness.

As there were 37 separate possible exposures listed in the main section of the RPQ, this paper describes only the responses to the single open-ended question. The quantitative data are the focus of a separate paper currently under review.

\section{Data analysis}

The text data were analysed using NVivo 9 (QSR International, 1999-2011), a qualitative data management software package. The responses for each person were initially reviewed by a single investigator (AT), and words or phrases from the text were coded within a scheme based on concepts identified from a range of sources $[8,9,14,19-24]$, as a form of directed content analysis [25].

After the initial review, the BCEES study team reviewed the categories, some example responses and any uncategorised text in order to further define and refine the coding definitions. A total of 37 categories were identified (including a category for 'don't know' responses), representing six major themes. Respondents who wrote that they didn't know, but then listed a number of possible causes were coded for the specific factors rather than 'Don't know'.

The coding definitions were then validated by two independent raters coding a random sample of responses. Discrepancies between raters were discussed with the BCEES study team and consensus was sought.

Analysis was conducted on the six higher level categories representing major themes in the data. These are described below:

\section{Physiological}

Included breast density and size, reproductive and hormonal profile, injury, disease and infection, immune system imbalance, sleep disturbance, medications, age, gender, and diagnostic delay. 


\section{Environmental}

Included environment, chemicals, food additives, radiation, domestic and personal care products, passive smoking, pesticides, and shiftwork.

\section{Familial}

Included family history and inheritable genetic mutations, and a universal gene or cell that could turn malignant.

\section{Mental/emotional}

Included stress, mental illness, and other psycho-social aspects.

\section{Modifiable/lifestyle}

Included alcohol, poor diet, overweight/obese, hormone replacement therapy, physical inactivity, smoking, substance abuse, and unhealthy lifestyle.

\section{Chance}

Included fate, religious causes and (bad) luck

The modifiable/lifestyle category comprised the factors which fall under personal control. All other higher-level categories were considered to contain non-modifiable factors.

In the results below, quotations in the respondent's exact words are used to illustrate causal attributions. The examples were chosen to demonstrate themes and are not necessarily representative of all respondents. Some editing has been necessary due to the length of some replies.

Descriptive analyses were conducted using Stata 12 (Statacorp, College Station, TX, USA).

Ethics approval for this project was received from the Human Research Ethics Committees of The University of Western Australia and the Department of Health Western Australia. All participants provided written informed consent.

\section{Results}

\section{Participants}

Case women were slightly younger, more likely to have a family history, and were more likely to have been born outside Australia and to have completed a university education than control women (Table 1). More than three-quarters of the participants provided one or more breast cancer causes in response to the open ended question in the RPQ (Table 1). However, case women twice as often responded 'Don't know' and gave, on average, fewer suggested causes for breast cancer (case mean 2.2 , control mean 3.1, based on the 37 concepts originally coded).

\section{Risk factors}

In the open ended questions (Table 2), case women reported mental/emotional factors most commonly (46\%),
Table 1 Demographic data for BCEES Risk Perception Questionnaire respondents: cases $(n=1109)$ and controls ( $n=1633)$

\begin{tabular}{|c|c|c|}
\hline & Cases N (\%) & Controls N (\%) \\
\hline \multicolumn{3}{|l|}{ Age at recruitment* } \\
\hline 49 years or less & $311(28.0)$ & 337 (20.6) \\
\hline $50-59$ years & $303(27.3)$ & $485(29.7)$ \\
\hline 60-69 years & $321(28.9)$ & $554(33.9)$ \\
\hline 70 years or older & $174(15.7)$ & $257(15.7)$ \\
\hline \multicolumn{3}{|l|}{ Country of birth } \\
\hline Australia or New Zealand & $700(63.1)$ & $1091(66.8)$ \\
\hline United Kingdom or Ireland & $250(22.5)$ & $347(21.2)$ \\
\hline Europe & $61(5.5)$ & $82(5.0)$ \\
\hline Asia & $56(5.0)$ & $60(3.7)$ \\
\hline Other & $42(3.8)$ & $53(3.2)$ \\
\hline \multicolumn{3}{|l|}{ Highest level of education* } \\
\hline Less than high school & $404(36.4)$ & $585(35.8)$ \\
\hline Completed high school & $223(20.1)$ & $368(22.5)$ \\
\hline Trade/apprenticeship & $241(21.7)$ & $398(24.4)$ \\
\hline Bachelor degree or higher & $241(21.7)$ & $282(17.3)$ \\
\hline \multicolumn{3}{|l|}{ Family history of breast cancer* } \\
\hline No & $668(60.2)$ & $1170(71.7)$ \\
\hline Yes & $438(39.5)$ & $459(28.1)$ \\
\hline \multicolumn{3}{|l|}{ Number of children } \\
\hline None & $138(12.4)$ & $176(10.8)$ \\
\hline 1 or more & $971(87.6)$ & $1457(89.2)$ \\
\hline \multicolumn{3}{|l|}{ Response* } \\
\hline One or more causes identified & $867(78.2)$ & $1288(78.9)$ \\
\hline Don't know & $163(14.7)$ & $131(8.0)$ \\
\hline No response & $79(7.1)$ & 214 (13.1) \\
\hline
\end{tabular}

*Characteristics that differ significantly $(\mathrm{p}<0.05)$ by Case-Control status

Table 2 Risk factor frequencies: BCEES cases $(n=871)$ and controls $(n=1297)$ who specified one or more causes

\begin{tabular}{lll}
\hline Risk factors $^{\text {a }}$ & Cases N (\%) & Controls N (\%) \\
\hline Mental/emotional & $404(46.4)$ & $388(29.9)$ \\
Modifiable/lifestyle & $336(38.6)$ & $611(47.1)$ \\
Physiological & $327(37.5)$ & $291(22.4)$ \\
Environmental & $271(31.1)$ & $589(45.4)$ \\
Genetic & $250(28.7)$ & $1006(77.6)$ \\
Chance & $78(9.0)$ & $84(6.5)$
\end{tabular}

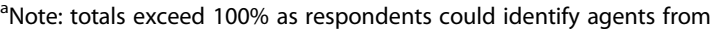
multiple categories. 
followed by modifiable/lifestyle factors (39\%) and physiological factors (38\%). For control women, familial factors were the most commonly reported causes of breast cancer $(78 \%)$, followed by modifiable/lifestyle $(47 \%)$ and environmental factors (45\%). Case women more often attributed a role in breast cancer causation to chance than control women (Table 2).

\section{Mental/emotional factors}

Almost half of the case women attributed their condition to some aspect of mental state, with a majority specifically citing stress. For many participants, specific stressful life events, including family-life or work-life, were conceptualised as 'triggers'. Respondents often described a string of events or processes, sometimes extending over many years, that played a causal role in their diagnosis with breast cancer.

"My inability to deal with a stressful situation over many years resulting in high anxiety and

sleeplessness...compounded by a sense of powerlessness over my ability to change the circumstances causing the stress". (Case, 50-54 years)

"Excessive stress, anxiety and lack of sleep leading to neglect in diet and lack of exercise and consumption of alcohol - binge drinking". (Case, < 45 years)

"Weakening of the immune system caused by stressful events... making my body lose its natural balance + trigger the cancer". (Case, 55-59 years)

Control women were less likely than case women to attribute the disorder to mental factors and stress. However, of those control women who did report stress as a casual factor, it was framed in similar terms to the case women.

\section{Familial factors}

The attribution of breast cancer to familial/genetic factors was the most commonly identified cause among control women, a proportion considerably higher than that for case women (Table 2). Control women also reported that the disease could be traced to a 'biological fault' which was often considered to lie dormant until a 'trigger', such as stress or exposure to pesticides, caused the development of a tumour:

"...I feel that everyone has a cell that contains cancer but some things trigger that cell to expand, maybe food, chemicals, pesticides or stress". (Control, 60-64 years)

"Imbalance in the body cells causes the cancer to become active; hereditary; certain type of genes carrying cancer cells". (Control, 50-54 years)

\section{Modifiable/lifestyle factors}

A substantial number of participants supplied one or more modifiable or lifestyle factors as breast cancer causes (Table 2). The most frequent attribution by case women in this category was hormone replacement therapy (HRT). Control women, in contrast, were more likely to attribute breast cancer to lifestyle factors such as poor diet, alcohol, smoking, or lack of exercise.

Women from both groups typically listed several different factors from this category:

\section{"...HRT increases the risk, as does alcohol consumption, obesity, smoking, lack of regular exercise". (Control, 45-49 years)}

"Lack of physical exercise resulting in weight gain in recent years. Stress; HRT" (Case, 65-69 years)

Many women also referred to specific foods, both insufficient and in excess. These references were generally combined with a range of other factors:

$$
\begin{aligned}
& \text { “.. - alcoholic soft drinks - a diet high in sugar..." } \\
& \text { (Case, }<45 \text { years) } \\
& \text { "... lot of red meat, no veges and healthy foods... } \\
& \text { exercise..." (Control, 50-54 years) }
\end{aligned}
$$

\section{Environmental factors}

Slightly more control women reported one or more environmental factors as risks for the disease, compared with case women (Table 2). Environmental factors which were mentioned included terms such as 'chemicals', 'pollution', and 'toxins', and alterations to food, such as 'additives,' 'preservatives,' 'pesticides' and 'processing'.

"...the modern environment with chemicals everywhere and in everything, including food, clothing, home, drink (water \& manufactured)....polluted air..." (Control, 60-64 years)

"...the cumulative effect of pesticides sprayed on the fruit and vegetables and gardens (went into drinking water). Genetically modified food, growth hormones in animal products, stress". (Case, 45-49 years)

A number of participants also attributed breast cancer development to radiation and more often mentioned non-ionising radiation, such as low frequency magnetic fields, than ionising radiation, such as X-rays and gamma $(\gamma)$-radiation:

"...Also I think factors such as power lines \& mobile phone towers play a big part for any type of cancer". (Control, 55-59 years) 
"... a network computing cabling box sits in that room [work office].... the radiation given off from that electromagnetic field must be enormous". (Case, 50-54 years)

\section{Physiological factors}

Case women were more likely to report one or more physiological agents as a cause of breast cancer than were control women (Table 2). The most common attributions were reproductive history and hormonal status, both of which are recognised risk factors for breast cancer [26-28]. Respondents also reported physical trauma of the breast as a causal agent.

"I accidently bumped my breast several times and I believe the result was a small lump that developed into cancer". (Case, 70 years and over)

\section{Discussion}

Almost $80 \%$ of participants provided one or more causes of breast cancer in response to the open-ended question on the RPQ. This finding is consistent with other studies on breast cancer from Australia and Canada [14,21], and studies of other cancer sites [26,29] which all confirm that a majority of people with or without a disease have thought about the causes of the disease. In many cases the attribution in this study was tentative, often accompanied by the phrase "I don't know, but...". The complex aetiology of breast cancer may explain much of this apparent indecision; it is generally acknowledged that interactions between numerous factors and agents are involved in the initiation and development of the disease [27,30-33].

A large proportion of respondents described more than one causal agent. However, case women gave fewer suggested causes for breast cancer and more often provided a 'Don't know' response, compared with control women. This may reflect the fact that case women were asked what they thought caused their own disease rather than the cause of breast cancer per se. Case women will generally have had some discussion with their medical practitioners in an attempt to pinpoint the aetiology of the disease and may have tried to identify a specific cause for their own disease. Previous studies have shown that women with cancer of varying types tend to attribute their disease to fewer agents than they recognise as causal factors for cancer in general [23].

The range of factors cited by respondents was comparable to those reported in previous studies, both those that asked open-ended questions [14,21] and those that used a checklist format $[12,34]$. The most common attribution in control women was familial factors, followed by modifiable/lifestyle and environmental factors, while the most common attribution in case women was mental/emotional factors, followed by modifiable/lifestyle and physiological factors. Two factors included in the Physiological category that are known to increase breast cancer risk, i.e., current age and age at menarche $[31,35]$, were not commonly cited by respondents.

\section{Mental/emotional factors}

In common with numerous other studies $[8,36,37]$ almost half of the case women attributed their own condition to stress or a particular mental state. Similarly, a substantial proportion of the control women associated stress with breast cancer development. The epidemiological evidence does not currently support stress as a risk factor for breast cancer [10,11], however many women in this study went on to link stress with other factors such as poor diet, lack of exercise and poor sleep. This could imply that, for many women, perceptions of breast cancer development involve a causal chain, with stress forming a vital link in the chain. Another perceived consequence of stress was disruption of the immune system, with a subsequent weakening of protection from developing cancer. As discussed by Wilcox and colleagues [8], there is some evidence for the effect of stress on both lifestyle choices and the immune system, and perhaps the progression of disease, but there is insufficient evidence that stress, either directly or indirectly, causes cancer [8].

\section{Familial factors}

The attribution of breast cancer development to inherited or genetic factors was the most commonly identified cause among control women, a finding previously reported by others $[12,24]$. For cases, genetic factors were less commonly mentioned as causes of their cancer. The different reporting of familial factors between the groups is likely to be because the cases would often know that a genetic cause was irrelevant to their own cancer.

While the BRCA gene mutations convey a much a higher risk to women who carry them, only a small number of women have the affected genotype, and known inheritable genetic mutations account for less than $5 \%$ of breast cancers with other familial risk bringing this to about $9 \%$ of breast cancer cases [38,39]. The perception of breast cancer as an inheritable condition may have implications for public health initiatives on prevention and early detection of the disease if women without a family history of the disease believe that they are not at risk. Education and prevention campaigns targeting breast cancer may need to focus much more strongly on the other identified risk factors for breast cancer, especially those factors that are readily modifiable, and stress the small proportion of breast cancers associated with genetic and familial factors. 


\section{Modifiable/lifestyle factors}

The most frequent attribution within the modifiable/ lifestyle category by case women was HRT (13.7\%). HRT has been identified as a risk factor for breast cancer, and this discovery was the subject of widespread media coverage and policy debate [40,41]. Given the extensive attention, it was predicted that both case and control women would identify HRT as a risk factor, but this was not the case. The variation in rates of attribution may result from case women having received information from medical professionals that increased their recognition of HRT as a risk factor, or it may represent a reflection of the different question asked of the two groups.

Within this category, control women were more likely to attribute breast cancer to lifestyle factors such as diet, alcohol, smoking, or lack of exercise. Alcohol consumption is a recognised risk factor for breast cancer [30,42], and moderate and vigorous exercise appears to act as a protective factor [43]. However, there is limited evidence to support a role for smoking or various aspects of diet in the development of the disease $[42,44,45]$. Similarly to reports from the USA [24], respondents identified 'unhealthy' factors such as smoking and diet, rather than those that are breast cancer-specific. One study identified that UK adults had limited knowledge of various aspects of lifestyle as risk factors for both cancer and heart disease [46], while a group from the USA also found poor knowledge of breast cancer risk factors [12]. Poor recognition of modifiable lifestyle factors is a significant barrier to effective public health campaigns aimed at disease prevention.

Some lifestyle factors were referred to, by both case and control women, as protective rather than causative: more vegetables and exercise, less fat, red meat and alcohol, and keeping a healthy weight. However, with the exception of low alcohol consumption, sufficient exercise and avoiding weight gain, there is little evidence that specific lifestyle factors protect against breast cancer development $[45,47]$.

\section{Environmental factors}

Slightly more control women reported one or more environmental factors as risks for breast cancer. However specific chemicals were rarely identified by participants, who generally referred to broad factors such as 'pollutants', 'toxins' or 'additives' in describing environmental risks.

A number of chemicals found in the environment, such as benzene (found in vehicle exhausts), are known carcinogens although with no definite connection to breast cancer $[5,42]$. Some pesticides have been shown to mimic the effects of oestrogen and it is plausible that they could increase breast cancer risk, although the current epidemiological evidence is weak $[5,48]$.
Exposure to ionising radiation, such as $\mathrm{x}$-rays, is a known risk factor for cancers of all types [49], but no role for non-ionising radiation in the development of breast cancer has been established [50,51]. In this study respondents were more likely to attribute breast cancer to non-ionising than to ionising radiation; this may reflect a poor understanding of the difference between the types of radiation, and the ubiquity of electronic and electrical devices in modern society. Other studies have reported similar attributions of cancer development to both types of radiation [8].

\section{Strengths of the study}

This study used an undirected, open-ended question to elicit the widest possible range of views as to breast cancer causation, similarly to some studies [23], and in contrast to studies based on a checklist of perceived causative factors $[12,19,22,24]$. In addition, the study had a large sample size of almost 3000 women. The large number of contributions enabled the investigation of nuances, such as the connection of stress with numerous other risk factors, in the causative attributions of women in Western Australia.

\section{Study limitations}

The relatively low response fraction for BCEES may have resulted in an unrepresentative sample. However, the similarity of the findings from this study with previous work across the globe encourages the belief that BCEES participants adequately represent the views of the wider population.

The inclusion of possible risk factors, such as power lines, in the 37-item checklist section of the RPQ which preceded the open-ended question, may have stimulated reporting of these items, to the detriment of other risk factors, such as age and gender, that did not form part of the checklist.

\section{Conclusion}

Overall, many of the risk factors cited by the participants do not correspond to those generally accepted by the scientific community [20]. Some of the divergence may arise from the tendency for negative results to not be published in the scientific literature, and if published, even less likely to be reported in the mass media. Thus one well-publicised study showing a small increase in breast cancer risk due to a particular food, for example, may not be displaced in the minds of the public by poorly-publicised future studies that fail to support the causative role. Second, there may be psychological reasons whereby assigning causation to external factors acts to preserve the individual from self-blame and guilt $[37,52]$. In other words, the person believes they have no 
control over the external exposure and therefore cannot be 'blamed' for getting breast cancer.

What is clear however, is that there is a discrepancy between attributed and scientifically-recognised risk factors and that this may have a significant impact on the success of prevention and early detection programs that seek to minimise the pain and suffering caused by this disease. Specifically, the inflated perception of genetic factors as a cause of breast cancer amongst women without breast cancer is a potential threat to the success of prevention and early detection programs. There is a need for research to identify what impact this poor understanding of the role of genetics may be having on mammographic screening, and a role for health promotion in raising awareness of the true role of genetics in breast cancer risk. In addition, the relatively poor recognition of the causative role of some modifiable lifestyle factors is a significant barrier to effective public health campaigns aimed at disease prevention.

There is a need for health promotion campaigns to raise awareness and improve knowledge of the scientificallyrecognised risk factors, in order to allow women to make informed choices about their health and healthcare options. There is a role for additional research to quantify the impact of these misperceptions on breast cancer risk and for health promotion to improve knowledge and awareness of risk factors with a strong evidence base.

\section{Abbreviations \\ BCEES: Breast cancer, environment \& employment study; HRT: Hormone replacement therapy; RPQ: Risk perception questionnaire.}

\section{Competing interests}

The authors declare that they have no competing interests.

\section{Author's contributions}

AT made substantial contributions to the recruitment of participants, data collection, analysis and interpretation of the data, and preparation of the manuscript draft. JH participated in the design of the study, analysis and interpretation of the data, and revised the manuscript. JG contributed to the design of the study, data collection, analysis and interpretation of the data, and revised the manuscript. TS assisted with the concept and design of the study and revised the manuscript. CS participated in the design of the study and revised the manuscript. LF contributed to the concept and design of the study, data analysis and interpretation, and revised the manuscript. All authors read and approved the final manuscript.

\section{Acknowledgements}

Other members of the BCEES team: Pierra Rogers, Terry Boyle, Sonia El-Zaemy, Ann D'Orsogna, Deborah Glass.

BCEES was funded by the National Health and Medical Research Council (\#572530) and the Cancer Council WA.

Lin Fritschi has a National Health and Medical Research Council Research Fellowship.

\section{Author details}

'School of Occupational Therapy and Social Work, Curtin University, GPO Box U1987, Perth, WA, Australia 6845. ${ }^{2}$ School of Population Health, The University of Western Australia, 35 Stirling Highway, Crawley, WA, Australia 6009. ${ }^{3}$ Western Australian Institute for Medical Research, The University of Western Australia, Ground Floor, B Block, QEll Medical Centre, Hospital Avenue, Nedlands, WA 6009, Australia. ${ }^{4}$ Cancer Council Western Australia, 15 Bedbrook Place, Shenton Park, WA, Australia 6008. ${ }^{5}$ School of Surgery, The
University of Western Australia, 35 Stirling Highway, Crawley, WA, Australia 6009. '5Chool of Public Health, Curtin University, GPO Box U1987, Perth, WA Australia 6845.

Received: 21 October 2013 Accepted: 12 August 2014

Published: 21 August 2014

\section{References}

1. Australian Institute of Health and Welfare (AlHW): Cancer in Australia: Actual incidence and mortality data from 1982 to 2007 and projections to 2010. Asia Pac J Clin Oncol 2011, 7(4):325-338.

2. Lee SH, Akuete K, Fulton J, Chelmow D, Chung MA, Cady B: An increased risk of breast cancer after delayed first parity. Am J Surg 2003, 186(4):409-412.

3. Boyd NF, Martin $L$, Rommens JM, Paterson AD, Minkin S, Yaffe MJ, Stone J, Hopper JL: Mammographic density: a heritable risk factor for breast cancer. In Methods of Molecular Biology, Cancer Epidemiology. Volume 472. Edited by Verma M. Totowa, NJ: Humana Press; 2009:343-360.

4. Willett WC: Diet and breast cancer. J Intern Med 2001, 249(5):395-411.

5. Gray J, Evans N, Taylor B, Rizzo J, Walker M: State of the evidence: the connection between breast cancer and the environment. Int/ J Occup Environ Health 2009, 15(1):43-78.

6. Coyle YM: The effect of environment on breast cancer risk. Breast Cancer Res Treat 2004, 84(3):273-288.

7. Messina CR, Kabat GC, Lane DS: Perceptions of risk factors for breast cancer and attitudes toward mammography among women who are current, ex- and non-smokers. Women Health 2002, 36(3):65-82.

8. Willcox S, Stewart B, Sitas F: What factors do cancer patients believe contribute to the development of their cancer? (New South Wales, Australia). Cancer Cause Control 2011, 22(11):1503-1511.

9. Wold KS, Byers T, Crane LA, Ahnen D: What do cancer survivors believe causes cancer? (United States). Cancer Cause Control 2005, 16(2):115-123.

10. McKenna MC, Zevon MA, Corn B, Rounds J: Psychosocial factors and the development of breast cancer: a meta-analysis. Health Psychol 1999, 18(5):520-531

11. Butow PN, Hiller JE, Price MA, Thackway SV, Kricker A, Tennant CC: Epidemiological evidence for a relationship between life events, coping style, and personality factors in the development of breast cancer. J Psychosom Res 2000, 49(3):169-181.

12. Burak L, Boone B: College women and breast cancer: knowledge, behavior, and beliefs regarding risk reduction. Am J Health Educ 2008, 39(4):206-212

13. Rabin C, Pinto B: Cancer-related beliefs and health behavior change among breast cancer survivors and their first-degree relatives. Psycho Oncol 2006, 15(8):701-712.

14. Stewart DE, Cheung AM, Duff S, Wong F, McQuestion M, Cheng T, Purdy L, Bunston T: Attributions of cause and recurrence in long-term breast cancer survivors. Psycho Oncol 2001, 10(2):179-183.

15. Girschik J, Fritschi L, Heyworth J, Waters F: Validation of self-reported sleep against actigraphy. J Epidemiol 2012, 22(5):462-468.

16. Fritschi L, Glass DC, Heyworth JS, Aronson KJ, Girschik J, Boyle T, Grundy A, Erren TC: Hypotheses for mechanisms linking shiftwork and cancer. Med Hypotheses 2011, 77(3):430-436

17. Fritschi L, Sadkowsky T, Benke GP, Thomson A, Glass DC: Triaging Jobs in a Community-Based Case-Control Study to Increase Efficiency of the Expert Occupational Assessment Method. Ann Occup Hyg 2011, 56(4):458-465

18. Girschik J, Heyworth J, Fritschi L: Self-reported Sleep Duration, Sleep Quality, and Breast Cancer Risk in a Population-based Case-Control Study. Am J Epidemiol 2013, 177(4):316-327.

19. Costanzo ES, Lutgendorf SK, Roeder SL: Common-sense beliefs about cancer and health practices among women completing treatment for breast cancer. Psycho Oncol 2011, 20(1):53-61.

20. Ferrucci LM, Cartmel B, Turkman YE, Murphy ME, Smith T, Stein KD, McCorkle R: Causal attribution among cancer survivors of the 10 most common cancers. J Psychosoc Oncol 2011, 29(2):121-140.

21. Lavery JF, Clarke VA: Causal attributions, coping strategies, and adjustment to breast cancer. Cancer Nurs 1996, 19(1):20-28.

22. Linn MW, Linn BS, Stein SR: Beliefs about causes of cancer in cancer patients. Soc Sci Med 1982, 16(7):835-839. 
23. Maskarinec G, Gotay CC, Tatsumura Y, Shumay DM, Kakai H: Perceived cancer causes. Cancer Pract 2001, 9(4):183-190.

24. Wang C, Miller SM, Egleston BL, Hay JL, Weinberg DS: Beliefs about the causes of breast and colorectal cancer among women in the general population. Cancer Cause Control 2010, 21(1):99-107.

25. Hsieh H-F, Shannon SE: Three approaches to qualitative content analysis. Qual Health Res 2005, 15(9):1277-1288.

26. Hankinson S: Endogenous hormones and risk of breast cancer in postmenopausal women. Breast Dis 2006, 24:3-15.

27. Lipworth L, Bailey LR, Trichopoulos D: History of breast-feeding in relation to breast cancer risk: a review of the epidemiologic literature. J Nat Cancer Inst 2000, 92(4):302-312.

28. Layde PM, Webster LA, Baughman AL, Wingo PA, Rubin GL, Ory HW: The independent associations of parity, age at first full term pregnancy, and duration of breastfeeding with the risk of breast cancer. J Clin Epidemiol 1989, 42(10):963-973.

29. Park N-J, Kang D-H: Breast cancer risk and immune responses in healthy women. Oncol Nurs Forum 2006, 33(6):1151-1159.

30. Lenz SK, Goldberg MS, Labreche F, Parent ME, Valois MF: Association between alcohol consumption and postmenopausal breast cancer: results of a case-control study in Montreal, Quebec, Canada. Cancer Cause Control 2002, 13(8):701-710.

31. McPherson K, Steel CM, Dixon JM: Breast cancer-epidemiology, risk factors, and genetics. Br Med J 2000, 321(7261):624-628.

32. Morimoto LM, White E, Chen Z, Chlebowski RT, Hays J, Kuller L, Lopez AM, Manson J, Margolis KL, Muti PC, Stefanick ML, McTiernan A: Obesity, body size, and risk of postmenopausal breast cancer: the Women's Health Initiative (United States). Cancer Cause Control 2002, 13(8):741-751.

33. Pike MC, Krailo MD, Henderson BE, Casagrande JT, Hoel DG: 'Hormonal' risk factors, 'breast tissue age' and the age-incidence of breast cancer. Nature 1983, 303(30):767-770.

34. Kulik L, Kronfeld M: Adjustment to breast cancer. Soc Work Health Care 2005, 41(2):37-57.

35. Iwasaki M, Tsugane S: Risk factors for breast cancer: epidemiological evidence from Japanese studies. Cancer Sci 2011, 102(9):1607-1614.

36. Panjari M, Davis SR, Fradkin P, Bell RJ: Breast cancer survivors' beliefs about the causes of breast cancer. Psycho Oncol 2012, 21(7):724-729.

37. Arman M, Backman M, Carlsson M, Hamrin E: Women's perceptions and beliefs about the genesis of their breast cancer. Cancer Nurs 2006, 29(2):142-148,

38. van der Groep P, van der Wall E, van Diest PJ: Pathology of hereditary breast cancer. Cell Oncol 2011, 34(2):71-88.

39. Eeles RA, Stratton MR, Goldgar DE, Easton DF: The genetics of familial breast cancer and their practical implications. Eur J Cancer 1994, 30 (9):1383-1390

40. Johansson H, Gandini S, Bonanni B, Mariette F, Guerrieri-Gonzaga A, Serrano D, Cassano E, Ramazzotto F, Baglietto L, Sandri MT, Decensi A: Relationships between circulating hormone levels, mammographic percent density and breast cancer risk factors in postmenopausal women. Breast Cancer Res Treat 2008, 108(1):57-67.

41. Haas J, Miglioretti D, Geller B, Buist D, Nelson D, Kerlikowske K, Carney P, Dash S, Breslau E, Ballard-Barbash R: Average household exposure to newspaper coverage about the harmful effects of hormone therapy and population-based declines in hormone therapy use. J Gen Internal Med 2007, 22(1):68-73.

42. Cogliano VJ, Baan R, Straif K, Grosse Y, Lauby-Secretan B, El Ghissassi F, Bouvard V, Benbrahim-Tallaa L, Guha N, Freeman C, Galichet L, Wild CP: Preventable exposures associated with human cancers. J Natl Cancer Inst 2011, 103(24):1827-1839.

43. Friedenreich CM, Neilson HK, Lynch BM: State of the epidemiological evidence on physical activity and cancer prevention. Eur J Cancer 2010, 46(14):2593-2604.

44. Bissonauth V, Shatenstein B, Fafard E, Maugard C, Robidoux A, Narod S, Ghadirian P: Risk of breast cancer among French-Canadian women, noncarriers of more frequent BRCA1/2 mutations and consumption of total energy, coffee, and alcohol. Breast J 2009, 15(Suppl 1):S63-S71.

45. de Vere White R, Hackman RM, Kugelmass J: The dogmas of nutrition and cancer: time for a second (and maybe third) look. Ann NY Acad Sci 2010, 1190 (Foods for Health in the 21st Century: A Roadmap for the Future):118-125.
46. Sanderson SC, Waller J, Jarvis MJ, Humphries SE, Wardle J: Awareness of lifestyle risk factors for cancer and heart disease among adults in the UK. Patient Edu Counsel 2009, 74(2):221-227.

47. Michels KB, Mohllajee AP, Roset-Bahmanyar E, Beehler GP, Moysich KB: Diet and breast cancer: A review of the prospective observational studies. Cancer 2007, 109(12 Suppl):2712-2749.

48. Brody JG, Moysich KB, Humblet O, Attfield KR, Beehler GP, Rudel RA: Environmental pollutants and breast cancer: epidemiologic studies. Cancer 2007, 109(12 Suppl):2667-2711.

49. International Agency for Research on Cancer: lonizing radiation, Part 1: $\mathrm{X}$ - and gamma ( $(\gamma)$-radiation, and neutrons. In IARC Monographs on the Evaluation of Carcinogenic Risks to Humans, Volume 75. Lyon, France: World Health Organization; 2000.

50. Baan R, Grosse Y, Lauby-Secretan B, El Ghissassi F, Bouvard V, Benbrahim-Tallaa L, Guha N, Islami F, Galichet L, Straif K: Carcinogenicity of radiofrequency electromagnetic fields. Lancet Oncol 2011, 12(7):624-626.

51. International Agency for Research on Cancer: Non-lonizing radiation, Part 1: static and extremely low-frequency (ELF) electric and magnetic fields In IARC Monographs on the Evaluation of Carcinogenic Risks to Humans, Volume 80. Lyon, France: World Health Organization; 2002.

52. Decruyenaere M, Evers-Kiebooms G, Welkenhuysen M, Denayer L, Claes E: Cognitive representations of breast cancer, emotional distress and preventive health behaviour: a theoretical perspective. Psycho Oncol 2000, 9(6):528-536.

doi:10.1186/1756-0500-7-558

Cite this article as: Thomson et al:: Beliefs and perceptions about the causes of breast cancer: a case-control study. BMC Research Notes 2014 7:558

\section{Submit your next manuscript to BioMed Central and take full advantage of:}

- Convenient online submission

- Thorough peer review

- No space constraints or color figure charges

- Immediate publication on acceptance

- Inclusion in PubMed, CAS, Scopus and Google Scholar

- Research which is freely available for redistribution 